\title{
Development of the FHR advanced natural circulation analysis code and application to FHR safety analysis
}

\author{
Z. Guo ${ }^{1,2,3}$, N. Zweibaum ${ }^{3}$, M. Shao ${ }^{4}$, L. R. Huddar ${ }^{3}$, P. F. Peterson ${ }^{3}$, S. Qiu ${ }^{1}$ \\ ${ }^{1}$ : Department of Nuclear Science and Technology, Xi'an Jiaotong University, Xi'an, 710049, \\ China \\ ${ }^{2}$ :School of Nuclear Science and Engineering, North China Electric Power University, \\ 102206,China \\ 3: Department of Nuclear Engineering, University of California, Berkeley, 4118 Etcheverry Hall, \\ Berkeley, CA 94720, USA \\ ${ }^{4}$ : Lawrence Berkeley National Laboratory, Berkeley, CA 94720, USA
}

\begin{abstract}
The University of California, Berkeley (UCB) is performing thermal hydraulics safety analysis to develop the technical basis for design and licensing of fluoride-salt-cooled, hightemperature reactors (FHRs). FHR designs investigated by UCB use natural circulation for emergency, passive decay heat removal when normal decay heat removal systems fail. The FHR advanced natural circulation analysis (FANCY) code has been developed for assessment of passive decay heat removal capability and safety analysis of these innovative system designs. The FANCY code uses a one-dimensional, semi-implicit scheme to solve for pressure-linked mass, momentum and energy conservation equations. Graph theory is used to automatically generate a staggered mesh for complicated pipe network systems. Heat structure models have been implemented for three types of boundary conditions (Dirichlet, Neumann and Robin boundary conditions). Heat structures can be composed of several layers of different materials, and are used for simulation of heat structure temperature distribution and heat transfer rate. Control models are used to simulate sequences of events or trips of safety systems. A proportional-integral controller is also used to automatically make thermal hydraulic systems reach desired steady state conditions. A point kinetics model is used to model reactor kinetics behavior with temperature reactivity feedback. The underlying large sparse linear systems in these models are efficiently solved by using direct and iterative solvers provided by the SuperLU code on high performance machines. Input interfaces are designed to increase the flexibility of simulation for complicated thermal hydraulic systems. This paper mainly focuses on the methodology used to develop the FANCY code, and safety analysis of the Mark 1 pebble-bed FHR under development at UCB is performed.
\end{abstract}

Keywords: FHR, natural circulation, code methodology

\section{Introduction}

The University of California, Berkeley (UCB) is developing methods to design and perform safety analysis for fluoride-salt-cooled, high-temperature reactors (FHRs) in collaboration with the Massachusetts Institute of Technology and University of Wisconsin (Scarlat et al., 2014). Flibe is the baseline coolant for FHRs, while Dowtherm A, a heat transfer oil, has been identified as an appropriate simulant fluid for scaled heat transfer 
experiments for FHRs (Bardet and Peterson, 2008) FHRs have inherently safe features, such as natural-circulation-driven systems to passively remove decay heat from the reactor core during design basis and beyond design basis accidents. UCB has developed a commercial design for a small modular FHR, the Mark 1 (Mk1) pebble-bed FHR (PB-FHR) (Peterson et al., 2014). The capability to perform steady-state and transient system analysis is a key issue for licensing new reactor designs. Best-estimate system codes play a key role in the licensing of nuclear technology because of the impracticality of executing full-scale safety-related experiments. However, current nuclear commercial codes, such as RELAP5-3D and Flownex, have mainly been developed for light water reactors, which require the use of comprehensive two-phase flow models. This capability is not required to simulate singlephase flow phenomena in FHRs, whose baseline coolant, flibe, remains liquid up to $1430^{\circ} \mathrm{C}$ at atmospheric pressure. The FHR advanced natural circulation analysis (FANCY) code has been developed specifically for FHR technology modeling(Guo et al., 2014). It has the capability to model the Mk1 PB-FHR power plant system behavior under steady state and transient conditions. FANCY has a modular structure, which makes it easy to be maintained and updated. Physical models can easily be modified and added to the code for specific FHR problems, sensitivity studies and uncertainty analysis. Verification and validation (V\&V) of the FANCY code is being performed, including detailed code-to-code comparison with established thermal hydraulic system codes such as RELAP5-3D and Flownex, and validation against experimental data from UCB's Compact Integral Effects Test (CIET) facility (Bickel et al., 2014; Huddar and Peterson, 2014). These efforts are detailed in a separate paper(Zweibaum et al., 2015). The current paper mainly focuses on the development methodology of the FANCY code and on preliminary safety analysis results for the Mk1 PBFHR that is based on equivalent model, including two kinds of anticipated transient without scram (ATWS), such as loss of force circulation (LOFC) and loss of heat sink (LOHS).

\section{System code model}

This chapter briefly describes the mathematic models of the FANCY code, which mainly includes the hydrodynamic model, heat structure model, coupled strategy model, closure model, reactor kinetic model, system control model, sparse matrix solve model.

\subsection{Hydrodynamic model}

The fluid governing equations in each $\mathrm{CV}$ that are based on integral balance laws implemented in the code are derived from the Navier-Stokes equations. These space and time averaging models are widely used in safety analysis codes for nuclear systems. They neglect the effects of small scale processes on macroscopic steady or transient phenomena. This assumption is compensated by the use of suitable closure models for friction factor and heat transfer coefficients, which are usually found from separate effect tests.

As shown in Fig. 1, in order to avoid odd-even decoupling between pressure and velocity , a staggered mesh method is used (Patankar, 1980). On a staggered grid, the scalar variables (pressure, density, total enthalpy, etc.) are stored in the cell centers of the control volumes, whereas the vector variables (velocity or momentum) are located at the cell faces. As a result, the main control volume and momentum control volume are obtained separately. This is different from a collocated grid arrangement, where all variables are stored in the same position. Staggered storage schemes are mainly used for structured grids for compressible or 
incompressible flow simulations. The hydrodynamic component can be classified as a general component without branches, such as pipe, reactor core channel, primary side or secondary side of a heat exchanger, or pump. If the system has additional branches like T-junctions, cross junctions, or multiple junctions, a specific branch model will be used.

After integration of the Navier-Stokes equations, the macroscopic mass, momentum, and energy governing equations are obtained on the staggered mesh. The finite volume scheme with first order upwind method, combined with time discretization using a semi-implicit scheme, are used to obtain the differential forms of the conservation equations, as shown in Eq. (1) - (4):

Mass conservation equation:

$$
A_{i} \frac{\rho_{i}^{n+1}-\rho_{i}^{n}}{\Delta t}+\frac{\rho_{v, i}^{n} u_{v, i}^{n+1} A_{v, i}-\rho_{v, i-1}^{n} u_{v, i-1}^{n+1} A_{v, i-1}}{Z_{i}}=0
$$

Momentum conservation equation:

$$
\begin{aligned}
& A_{v, i} \frac{\rho_{v, i}^{n} i_{v, i}^{n+1}-\rho_{v, i}^{n} u_{v, i}^{n}}{\Delta t}+\frac{\rho_{i+1}^{n}\left(u_{i+1}^{n}\right)^{2} A_{i+1}-\rho_{i}^{n}\left(u_{i}^{n}\right)^{2} A_{i}}{Z_{v, i}} \\
& =-\frac{P_{i+1}^{n+1} A_{i+1}-P_{i}^{n+1} A_{i}}{Z_{v, i}}-\rho_{v, i}^{n} A_{v, i} \sin \theta+\frac{\Delta P_{p u m p}}{Z_{v, i}}-\frac{1}{2 D_{v, i}}\left(f_{i}+\frac{K}{Z_{v, i}}\right) \rho_{v, i}^{n}\left|u_{v, i}^{n}\right| u_{v, i}^{n} A_{v, i}
\end{aligned}
$$

Energy conservation equation:

$$
V_{i}\left[\rho_{i}^{n} \frac{H_{i}^{n+1}-H_{i}^{n}}{\Delta t}+H_{i}^{n} \frac{\rho_{i}^{n+1}-\rho_{i}^{n}}{\Delta t}\right]+(\rho H)_{v, i}^{n} u_{v, i}^{n+1} A_{v, i}-(\rho H)_{v, i-1}^{n} u_{v, i-1}^{n+1} A_{v, i-1}=Q_{i}
$$

Coolant state equation:

$$
\frac{\rho_{i}^{n+1}-\rho_{i}^{n}}{\Delta t}=\frac{\partial \rho(p, H)_{i}^{n}}{\partial H} \frac{H_{i}^{n+1}-H_{i}^{n}}{\Delta t}+\frac{\partial \rho(p, H)_{i}^{n}}{\partial p} \frac{p_{i}^{n+1}-p_{i}^{n}}{\Delta t}
$$

The pump head is added to the momentum model to simulate forced circulation. Although the fluid is assumed to be incompressible, the mass conservation equation considers the effect of thermal expansion by including the density derivative term with respect to time. Wall friction forces are neglected in the energy equation, so no dissipation rate is considered in the energy model. Because fluid density is independent of pressure for the single-phase, incompressible molten salt, the partial derivative of density with respect to pressure is also neglected.

The fluid mass, energy and momentum equations are coupled and then reduced to a pressure equation in one momentum $\mathrm{CV}$. A linear system of equations is obtained, which can be further reduced to $N$ linear equations for pressure, as shown in Eq. (5).

$$
A\left[\begin{array}{c}
\Delta P_{1} \\
\vdots \\
\Delta P_{i-1} \\
\Delta P_{i} \\
\Delta P_{i+1} \\
\vdots \\
\Delta P_{N}
\end{array}\right]=B
$$

$N$ is the total number of CVs, $A$ is an $N \times N$ sparse matrix, and $B$ is an $N$-dimensional vector. $A$ and $B$ are determined by the previous time step value. The non-zero elements in the matrix reflect the relationships between pressures among the main CVs, and upstream and downstream neighboring CVs. The sparse matrix is solved at each time step to get a new 
pressure distribution. Updated flow velocities and thermal properties are obtained from the new pressure distribution at each time step.

Each leg of branch is characterized by individual form loss coefficient. Since branches can have multiple inlets and outlets, the mass and energy equations for the branch model contains more than one advection term in governing equations.

For a staggered mesh, an appropriate interpolation model must also be considered. The first order upwind method is employed to avoid numerical oscillation Eq. (6)) (Patankar, 1980), where $\phi$ means thermal properties. The thermal properties of the momentum CV are updated based on the velocity direction.

$$
u_{i} \phi_{v, i}=\phi_{i-1} \max \left\{u_{i}, 0\right\}-\phi_{i} \max \left\{-u_{i}, 0\right\}
$$

Special attention should be paid on the angle interpolation for momentum CV which is a junction that connects two adjacent main CVs. Using a simple linear interpolation may introduce additional driving forces or resistances in the loop, which will cause significant distortions and increase uncertainty in code results when modeling natural circulation, where mass flow rates are usually small.

Fig. 2 shows a simple method to get the angle of a junction (momentum $\mathrm{CV}$ ) between pipes main $\mathrm{CVs}$ is to use a simple linear interpolation, $\theta_{4}=\left(\theta_{1}+\theta_{2}\right) / 2$. However, if we use angle $\theta_{4}$ to derive pipe elevation, the resulting effective height, $H_{4}$, is larger than the real height, $H_{3}$, leading to higher hydrostatic pressure. Instead, it is better to use a more accurate angle interpolation $\theta_{3}$ (Eq. (7)).

$$
\theta_{3}=\arcsin \left[\frac{H_{3}}{L_{3}}\right]=\arcsin \left[\frac{L_{1} \sin \theta_{1} / 2+L_{2} \sin \theta_{2} / 2}{\left(L_{1}+L_{2}\right) / 2}\right]
$$

Because $\theta_{3}$ is calculated from the actual effective height, no artificial driving force or resistance is introduced.

\subsection{Staggered mesh generation model}

For a large disperse region like a pipe network, mesh generation is harder to implement, especially when there are multiple connected or disconnected loops. Graph theory is used to generate, organize and store a staggered mesh of complicated pipe networks in disperse region. Basic information for hydrodynamic components, including pipes and branches, as well as their relationships are then defined, and an element-node (branch-node) incidence matrix is generated following graph theory matrix pattern (Bondy and Murty, 1976; Deo, 2004).

Fig. 3 shows a simple hydrodynamic system with two individual loops connected by two branches, and only one main $\mathrm{CV}$ in each hydrodynamic component. This system is represented by an $n \times m$ incidence matrix $A=\left(a_{i j}\right)$. Each row of the matrix is a junction index and each column is a hydrodynamic component index. $a_{i j}=1$ if junction $i$ connects to component $j$, $a_{i j}=-1$ if junction $i$ connects from component $j$, and $a_{i j}=0$ if junction $i$ is not adjacent to component $j$. The corresponding small incidence matrix is generated from relationships between hydraulic components, derived from input information. Furthermore, each hydraulics component 
can be sub-divided into more than one CV obtain a mesh-independent solution (Wang et al., 2010). Consequently, a new element-node (branch-node) incidence matrix is automatically generated based on the actually number of CVs in each component.

Moreover, some characteristics of the incidence matrix can be used to check whether mesh generation is logical or not. First, the $\infty$-norm of the matrix must be equal to 2 , and the row sum of matrix must be equal to zero, since each junction (momentum CV) only connects to two adjacent main CVs (mass/energy CVs). The 1-norm of the matrix must be greater than or equal to 2. Besides, the new element-node (branch-node) incidence matrix is useful to generate the adjacency matrix and tree for directed graph, which are necessary to set up initial conditions and check whether the hydraulic loop is closed.

\subsection{Heat structure model}

The heat structure model is added to the code for simulation of heat transfer into and across solid boundaries of hydrodynamic volumes. Spatial finite difference approximation is used to obtain the finite differential form of the heat conduction equation. Fig. 4 shows the mesh point layout. Thermal properties at a CV interface can be derived from interpolation from neighboring mesh nodes. The fully implicit form of the finite difference approximation for the heat conduction model at internal mesh nodes is as follows:

$$
\left(T_{m}^{n+1}-T_{m}^{n}\right) \frac{G_{m}}{\Delta t}=\left(T_{m-1}^{n+1}-T_{m}^{n+1}\right) k_{l m} \delta_{l m}^{s}+\left(T_{m+1}^{n+1}-T_{m}^{n+1}\right) k_{r m} \delta_{r m}^{s}+Q\left(\delta_{l m}^{v}+\delta_{r m}^{v}\right)
$$

Where $\delta$ and $G_{m}$ is the factors depend on geometry (rectangular, cylindrical and spherical geometries).

As is shown in Fig. 5, the mesh of the heat structure model consists of different spacings (non-uniform mesh), varying materials and different boundary conditions (Dirichlet, Neumann and Robin boundary conditions). There are fine mesh in regions where temperature gradients are large and coarse mesh in regions where temperature gradients are small. Besides, any radial node can be used as a boundary point to divide varying materials or heat sources in the mesh. The model automatically calculates both the right and left CVs for each radial node and sums up the volumes to get the right power density within specific material layer intervals for different types of geometry.

\subsection{Closure models}

The closure models in FANCY comprise the thermophysical properties of the fluid, friction factors and heat transfer coefficients. Thermophysical properties of Flibe and Dowtherm A have been added to FANCY so that scaled experimental loops using the simulant oil and FHR thermal hydraulics can be simulated. All fluid thermophysical properties depend on temperature and are independent of pressure for single-phase flow (GROUP, 2013). Thermophysical properties of stainless steel and copper - candidate materials for the FHR and scaled heat transfer loops using Dowtherm $\mathrm{A}$ - have also been included. For graphite in the pebble fuel, empirical correlations from AVR fuel are employed, which consider both temperature and fast neutron irradiation effects on fuel thermophysical properties (GROUP, 2001). Thermophysical properties of TRISO particles are independent of temperature (Cho et al., 2009).

The main friction factor and Nusselt number correlations are shown in Table 1. The proper choice of semi-empirical correlations determines the accuracy of simulation results. The trend 
and distribution of temperatures during transients is mainly based on heat transfer coefficients. If the Nusselt number is lower, peak temperatures during transient scenarios will be higher. In order to conservatively estimate temperatures in the system and guarantee safety of the reactor, sensitivity studies for heat transfer coefficients are necessary.

\subsection{System control model}

For safety analysis as well as risk analysis of the Mk1 PB-FHR and system simulation for the CIET loop, a sequence of events or actions is modelled. A control logic tree can be used to model system control and the decision making process based on Boolean algebra (Fig. 6). Besides, FANCY uses proportional and integral controls to make simulations converge faster under steady state.

\subsection{Reactor kinetics model}

The point kinetics model is used to obtain reactor power based on temperature reactivity feedback. This model is adequate when the spatial distribution of power can be assumed nearly constant. Due to the lack of neutronics experimental data for PB-FHRs, the kinetic parameters from gas-cooled reactors are employed (GROUP, 2001). The reactivity feedback model considers varying space effects, and the temperature feedback coefficients are obtained from MCNP5 calculations of the Mk1 PB-FHR core (Cisneros Jr, 2013), as shown in Table 2. Weight factors are used in the reactivity feedback model to take into account neutron worth at various locations in the reactor core.

When the reactor is shut down and power is below $5 \%$ of nominal power, a specific decay heat curve for the Mk1 PB-FHR is employed, derived from three classes of isotopes in ORIGEN - actinides, fission and activation products (Cisneros Jr, 2013):

\subsection{Sparse matrix solver model}

The major computational work is to solve a sequence of linear systems at each time step.

$$
A\left(t_{i}\right) x\left(t_{i}\right)=B\left(t_{i}\right)(i=0,1, \cdots, L)
$$

As the coefficient matrices are sparse, the generalized minimal residual (GMRES) method (Saad and Schultz, 1986) with right preconditioning is used to solve these linear systems. Since $A(t)$ and $B(t)$ depend continuously on $t$, except when step changes happen in the system (e.g. pump coastdown, reactor power level change, valve opening or closing), the solution $x(t)$ is also continuous. Therefore, $x\left(t_{i-1}\right)$ serves as an initial guess for GMRES when solving $A\left(t_{i}\right) x\left(t_{i}\right)=B\left(t_{i}\right)(i=0,1, \cdots, L)$. In addition, we propose the following preconditioning strategy for GMRES. Initially, $x\left(t_{o}\right)=A\left(t_{o}\right)^{-1} B\left(t_{o}\right)$ is solved using a sparse direct method based on sparse LU factorization (Demmel et al., 1999). Then $A\left(t_{o}\right)^{-1}$ is used as the preconditioner for GMRES at subsequent time steps. If GMRES fails to converge after five iterations at time $t_{i}$, we

compute $x\left(t_{i}\right)$ using the sparse direct method, and replace the preconditioner by $A\left(t_{i}\right)^{-1}$. This strategy adaptively updates the preconditioner when it deteriorates, ensuring the rapid convergence of GMRES. It has been observed that this strategy provides a good compromise between the convergence of GMRES and the expense of building preconditioners. Moreover, the reliability of the solution is retained even if GMRES fails to converge. In the FANCY code, both 
the sparse direct solver and the iterative GMRES solver are performed by the sparse matrix solver code (SuperLU version 4.3 (Li et al., 2011)), which is compiled together with FANCY source code. As a result, FANCY code has the capability to simulate transient problems for large scale systems.

\section{Code development and application}

\subsection{Code architecture}

FANCY is a system code based on module technology in Fortran 95, which can compile and execute both on Windows and Linux platforms. All individual models are explicitly coupled in the code structure, as shown in Fig. 7. Although relationships between various functions in the source code are complicated, the code has a user-friendly input deck, and the source code does not need to be modified to model specific thermal hydraulic systems. Furthermore, for advanced applications, each main module has its corresponding set of source code files, which can be modified or updated to add new closure models (e.g. heat transfer coefficient correlations, friction factor correlations, new materials thermal properties, etc.). Each source file has a single purpose, making the whole code easy to maintain and update. Development of the code is under strict version control, using professional version control tools for computer code development. All changes to the code are documented to support future development.

\subsection{Code Verification and Validation}

The verification of natural circulation model is done by comparing the code simulation result with steady-state analytical calculations for a simplified natural circulation loop without parasitic heat loss and form loss along the piping and it is shown that the simulation results of FANCY code agree well with analytical solution (Guo et al., 2014).

Detailed code-to-code comparison with established thermal hydraulic system codes such as RELAP5-3D, and validation against experimental data from UCB's Compact Integral Effects Test facility are performed in a separate paper (Zweibaum et al., 2015). The study shows that both RELAP5-3D and FANCY provide excellent predictions of steady-state natural circulation experiment in CIET 1.0, with mass flow rates within 13\% of experimental data, suggesting that both codes are good candidates for design and licensing of FHR technology.

\subsection{Nodalization of the Mk1 PB-FHR model}

Fig. 8 and Fig. 9 show the Mk1 PB-FHR system and the corresponding nodalization diagram, based on an equivalent model of the Mk1 PB-FHR. In the equivalent model, the two coiled tube air heater (CTAH) loops, which transfer heat from the primary loop of the reactor to air in the nuclear Air-Brayton combined cycle, are combined into one equivalent loop. Similarly, the three direct reactor auxiliary cooling system (DRACS) loops, used to passively remove decay heat with natural circulation when the normal shutdown cooling system does not function, are combined into one loop. The reactor core is modelled as a one-dimensional component along the axial direction and radial flow is not modelled. This simplification of the Mk1 PB-FHR thermal hydraulic systems into an equivalent model is the first step in analyzing transient responses of this class of reactors. For $\mathrm{V} \& \mathrm{~V}$ purposes, results from this analysis will be compared to experimental data from the CIET facility (Bickel et al., 2014), since CIET scaling was also based 
on an equivalent model of the PB-FHR. It is worth noting that failure of individual CTAH or DRACS loops cannot be studied using the equivalent model. For example, if loss of force circulation happens in CTAH loop, two CTAH loops will both have pump coast down at the same time. Consequently, it can be regards as conservative safety analysis.

\section{Simulation results}

\subsection{Loss of forced circulation}

The top graph in Fig. 10 shows the effect of reactivity on power ratio (the ratio of actual power to nominal, normal operation power). The middle graph shows the comparison between the power ratio and the mass flow ratio (the ratio of actual mass flow rate to nominal, normal operation mass flow rate). These competing effects between power and mass flow rate finally decide whether reactor coolant temperature increase or not, as shown in the bottom graph. The time scales of the three graphs are linked to illustrate the underlying relationship between reactor power, reactivity feedback, temperatures and mass flow rate. With the help of a PI controller, pump head is adjusted automatically to make the system reaches designed steady state before $1400 \mathrm{~s}$. One of the studied accident scenarios is unprotected loss of forced circulation (LOFC). In this case, the reactor power response only depends on the system's negative temperature reactivity feedback. The sequence of events is as follows: pump coastdown happens at $1400 \mathrm{~s}$. Due to lack of pump coastdown data in pre-conceptual design phase of Mk1 PB-FHR, the molten salt reactor experiment (MSRE) pump coast down curve (Guo et al., 2013; Pince et al., 1968) is used temperately. A check valve located in the DHX branch opens approximately $45 \mathrm{~s}$ when there is small mass flow reversal in DHX shell side after pump coastdown. The check valve open time is determined by the static differential pressure of fluid and pressure force needed to open the check valve mechanism that is determined by check valve design.

This LOFC transient can be divided into three main time phases (Fig. 10): during the first phase (before $1400 \mathrm{~s}-1450 \mathrm{~s}$ ), the coolant temperature increases as the reactor core mass flow rate drops, which triggers negative temperature reactivity feedback. Consequently, the reactor power starts to decrease. However, the mass flow rate ratio decreases more rapidly than the power ratio. These competing effects cause the coolant temperature to continue increasing. During the second phase (1450 s $-1530 \mathrm{~s})$, the hydrostatic pressure difference between the inlet and outlet of the check valve increases enough to cause it to open. The natural circulation mass flow rate from the reactor core to the DHX increases. Furthermore, when the power ratio equals the mass flow ratio, $128 \mathrm{~s}$ after the LOFC happens, the core outlet coolant temperature reaches its peak temperature. As the DHX outlet temperature increases, the core inlet temperature increases significantly. During the third phase (1530 s - end), the power ratio continues to decrease with negative reactivity feedback, and the increase in heat transfer from the shell side of the DHX to the DRACS loop causes the DHX shell side outlet temperature and the reactor core inlet temperature to drop. Natural circulation from the core to the DHX starts to reach quasisteady state and the mass flow ratio is larger than the power ratio, causing the coolant temperature to further decrease. The decay heat from actinides, fission products and activation products is then the dominant heat source in the reactor core at this phases and the DRACS system works to extract the decay power.

As shown in Fig. 11, from $200 \mathrm{~s}$ to $400 \mathrm{~s}$, the system reaches steady state by using a PI control algorithm. $100 \%$ mass flow rate goes through the CTAH, $96.7 \%$ goes through the core 
and 3.3\% goes through the DHX shell side, transferring heat to the DRACS loop to prevent the flibe in the DRACS loop from freezing. As a result, the DRACS loop has a minor natural circulation flow $(9 \mathrm{~kg} / \mathrm{s})$ in normal operation. Additionally, there is a $7 \%$ bypass flow in the reactor core, through graphite reflectors, control rod insertion channels and injection lines. When pump coastdown happens without check valve open, the total system mass flow rate is at $30 \mathrm{~kg} / \mathrm{s}$, which is derived from small natural circulation both from reactor core to CTAH and reactor core to DHX. Specifically, $100 \%$ of this flow goes through the reactor core, $75 \%$ goes through the CTAH and 25\% goes through the DHX. The flow rate direction reverses in the DHX because during natural circulation operation, the flow direction is from the top inlet to the bottom outlet of the DHX shell side. The check valve opens $45 \mathrm{~s}$ into the LOFC transient and the initial natural circulation driving force causes the flow rate in the DHX shell side and the reactor core to increase dramatically. $84 \%$ of the total system flow goes through the DHX and $16 \%$ goes through the CTAH. The reactor power ratio is 0.16 . As heat transfer from the DHX shell side to tube side increases, the natural circulation flow rate increases gradually in the DRACS loop (TCHX mass flow rate in Fig. 11). At $3600 \mathrm{~s}$, the system reaches long term steady state conditions. The power ratio is 0.15 and the flow rate in the CTAH is negligible $(0.017 \mathrm{~kg} / \mathrm{s})$. Therefore, decay heat is mainly extracted by the DRACS system.

\subsection{Loss of heat sink}

Loss of heat sink (LOHS) without scram happens if the power conversion system fails, or if a pipe in the secondary air loop breaks, and reactor scram does not occur. In such conditions, the CTAH cannot remove heat from the reactor core. Fig. 12 shows the results of this transient as modeled in FANCY. The transient can be divided into four phases: during the first phase (1400 s - $1450 \mathrm{~s}$ ), the CTAH stops functioning as a heat sink, causing average temperature of CTAH increases. Consequently, since the pump speed as well as pump head remain almost constant, the total system mass flow rate increases to match the pump head because the flibe coolant viscosity decreases due to an increase in coolant temperature. This means the shear stress of the fluid drops, and thus the friction pressure drops. Besides, the reactor core average temperature decreases slightly because reactor mass flow rate increase, which introduces a small positive reactivity feedback and causes the power to increase by $4 \%$. However, since the mass flow ratio increases faster than the power ratio, the reactor core outlet temperature decreases. During the second phase $(1450 \mathrm{~s}-1500 \mathrm{~s})$, hot coolant returns to the core inlet because there is no heat removal from the CTAH. The fluid residence time for the primary loop is approximately $70 \mathrm{~s}$. Consequently, the reactor core inlet and average temperatures increase significantly, which introduces strong negative reactivity feedback and reduces power level. As a result, the coolant temperature in the core stops increasing (Fig. 12, bottom graph). During the third phase (1500 s $1600 \mathrm{~s}$ ), the reactor core temperature and the total mass flow rate oscillate slightly with a time period of about $100 \mathrm{~s}$. Flibe is a high-Prandtl-number fluid and the viscosity is strongly depends on the temperature. Friction losses dominate form losses in the Mk1 PB-FHR system. An increase in coolant temperature lowers viscosity of the coolant, causing an increase in mass flow rate to meet the pump head, which reduces coolant temperature. Conversely, a decrease in temperature makes the viscosity of the fluid increase, causing mass flow rate to decrease to meet the pump head. This in turn causes an increase in coolant temperature. This oscillation process is damped by thermal inertia of structural materials and temperature reactivity feedback in the core, and will therefore stop when equilibrium is reached. During the last phase (1600 s - $1900 \mathrm{~s})$, 
decay heat is the main heat source in the reactor core. The mass flow ratio stabilizes at a value of 1.2 and the peak coolant temperature is $727^{\circ} \mathrm{C}$ with a $2^{\circ} \mathrm{C}$ temperature rise in the reactor core.

The system average temperature increases after the LOHS transient, as shown in Fig. 13, which makes the viscosity of the fluid decrease. As a result, the mass flow rate increases to match the pump head. Within $240 \mathrm{~s}$ after LOHS happens, the system total mass flow rate increases by $22 \%$ and makes the DHX shell side bypass flow increase by $32 \%$. Consequently, the heat transfer rate of the DHX increases to remove more energy from the primary coolant. The natural circulation mass flow rate in the DRACS loop increases by 2.3 times and reaches $20 \mathrm{~kg} / \mathrm{s}$. However, since the reactor power decreases because of negative reactivity feedback and mass flow rate increases, the coolant temperature rise in the reactor core drops significantly from $100^{\circ} \mathrm{C}$ to $2^{\circ} \mathrm{C}$. Subsequently, the average temperature of the flibe decreases slightly because the decay power is gradually removed by the DRACS loop. Simultaneously, friction losses increase gradually and the corresponding total system mass flow rate decreases to meet the pump head.

\title{
5. Conclusion
}

The mathematical model and numerical discretization used in the development of the FANCY system analysis code have been described. FANCY is specifically designed for FHRs with clear modular structure to be maintained and updated, since it is easy to add new heat transfer model as well as hydraulic models from detailed separate effect test in the future. This code has user-friendly input deck to model complicated thermal hydraulics system, which is based on object-oriented concept. FANCY code employs state of the art faster sparse matrix solver to make it has the capability to model large-scale thermal hydraulic system problem. Besides this code can model sequence of events, which is import for safety as well as risk analysis for license of new concept reactor. Detailed code-to-code comparisons and validation are performed in a companion paper from $\operatorname{UCB}(Z$ weibaum et al., 2015). Accident transients LOFC and LOHS relevant to the Mk1 PB-FHR design were analyzed. The analysis was performed based on an equivalent model, yielding conservative results. The passive mechanisms in the design of the Mk1 PB-FHR guarantee reactor safety during accident transients.

\section{ACKNOWLEDGMENTS}

The National Natural Science Foundation of China (NSFC) (Grant No. 91326201), China Scholarship Council (CSC) and U.S. Department of Energy Office of Nuclear Energy's Nuclear Energy University Programs are gratefully for providing funding support for this work. The authors thank Xiaoye S. Li for helpful discussions.

\author{
Acronyms and Abbreviations \\ FHR: Fluoride-salt-cooled, high-temperature reactor \\ $\mathrm{CV}$ : control volume \\ DHX: DRACS heat exchanger \\ DRACS: Direct reactor auxiliary cooling system \\ CTAH: Coiled tube air heater \\ TCHX: Thermosyphon-cooled heat exchanger (in DRACS) \\ NACC: Nuclear air-Brayton combined cycle
}




\begin{tabular}{|c|c|}
\hline \multicolumn{2}{|c|}{ Nomenclature } \\
\hline$A$ & Cross section area $\left(\mathrm{m}^{2}\right)$ \\
\hline$D$ & Hydraulics diameter(m) \\
\hline$f$ & Friction factor \\
\hline$g$ & Gravitational acceleration $\left(\mathrm{m} / \mathrm{s}^{2}\right)$ \\
\hline$H$ & Enthalpy $(\mathrm{J} / \mathrm{kg})$ \\
\hline$k$ & Heat conductivity coefficient $\left(\mathrm{W} / \mathrm{m} \cdot{ }^{\circ} \mathrm{C}\right)$ \\
\hline$N u$ & Nusselt number \\
\hline$Q$ & Power(W) \\
\hline$R e$ & Reynolds number \\
\hline$P$ & Pressure $(\mathrm{Pa})$ \\
\hline$\Delta P$ & Pressure change $(\mathrm{Pa})$ \\
\hline$\Delta t$ & Time difference(s) \\
\hline$T$ & Temperature $\left({ }^{\circ} \mathrm{C}\right)$ \\
\hline$u$ & Velocity $(\mathrm{m} / \mathrm{s})$ \\
\hline$V$ & $\operatorname{Volume}\left(\mathrm{m}^{3}\right)$ \\
\hline$Z$ & Axial position difference $(\mathrm{m})$ \\
\hline$\phi_{i}$ & Thermal property \\
\hline$\theta$ & Inclination angle(rad) \\
\hline$\rho$ & Density(kg/s) \\
\hline \multicolumn{2}{|c|}{ Subscripts } \\
\hline$v, i$ & Momentum control volume number \\
\hline$i$ & Mass/Energy control volume number \\
\hline \multicolumn{2}{|c|}{ Superscript } \\
\hline$n$ & Time step \\
\hline
\end{tabular}

\section{REFERENCES}

Bardet P.M., Peterson P.F., (2008), Options for scaled experiments for high temperature liquid salt and helium fluid mechanics and convective heat transfer. Nuclear Technology 163, 344-357. 
Bickel J.E., Zweibaum N., Peterson P.F., (2014), Design, Fabrication and Startup Testing in the Compact Integral Effects Test (CIET 1.0) Facility in Support of Fluoride-Salt-Cooled, HighTemperature Reactor Technology. Department of Nuclear Engineering, USA.

Bondy J.A., Murty U.S.R., (1976), Graph theory with applications. Macmillan London.

Cho N.Z., Yu H., Kim J.W., (2009), Two-temperature homogenized model for steady-state and transient thermal analyses of a pebble with distributed fuel particles. Annals of nuclear energy 36, 448-457.

Churchill S.W., Chu H.H.S., (1975), Correlating equations for laminar and turbulent free convection from a vertical plate. International Journal of Heat and Mass Transfer 18, 1323-1329.

Cisneros Jr A.T., (2013), Pebble Bed Reactors Design Optimization Methods and their Application to the Pebble Bed Fluoride Salt Cooled High Temperature Reactor (PB-FHR). UNIVERSITY OF CALIFORNIA, BERKELEY.

Demmel J.W., Eisenstat S.C., Gilbert J.R., Li X.S., Liu J.W., (1999), A supernodal approach to sparse partial pivoting. SIAM Journal on Matrix Analysis and Applications 20, 720755.

Deo N., (2004), Graph theory with applications to engineering and computer science. PHI Learning Pvt. Ltd., USA.

Dittus F., Boelter L., (1985), Heat transfer in automobile radiators of the tubular type. International Communications in Heat and Mass Transfer 12, 3-22.

Ergun S., (1952), Fluid flow through packed columns. Chem. Eng. Prog. 48.

GROUP I., (2001), Afterheat Removal for Gas Cooled Reactors Under Accident Conditions, IAEA-TECDOC-1163. International Atomic Energy Agency., Vienna, Austria.

GROUP T.H., (2013), Temperature -Dependent Thermophysical Properties for Fluoride Salts and Simulant Fluids University of California, Berkeley, USA.

Guo Z., Scarlat R.O., Huddar L., Zweibaum N., Peterson P.F., Qiu S., Su G., (2014), Verification and Validation of a Natural Circulation Loop Model for FHRs, Advances in Thermal Hydraulics (ATH '14), Reno,Nevada, USA.

Guo Z., Zhang D., Xiao Y., Tian W., Su G., Qiu S., (2013), Simulations of unprotected loss of heat sink and combination of events accidents for a molten salt reactor. Annals of Nuclear Energy 53, 309-319.

Huddar L., Peterson P.F., (2014), Separate Effects Tests in Support of Heat Transfer Characterization in Fluoride-Salt-Cooled High Temperature Reactors, UCBTH-14-010. Department of Nuclear Engineering, University of California, Berkeley.

Krumwiede D.L., Laufer M.R., Munk M., Scarlat R.O., Zweibaum N., Greenspan E., Peterson P.F., (2014), Technical Description of the Mark -1 Pebble-Bed Fluoride-Salt-Cooled High-Temperature Reactor (PB-FHR) Power Plant, UCBTH-14-002. Department of Nuclear Engineering,UC, Berkeley, USA.

Li X.S., Demmel J.W., Gilbert J.R., Grigori L., Shao M., Yamazaki I., (2011), SuperLU users' guide.

Nield D.A., Bejan A., (2006), Convection in porous media. springer.

Patankar S.V., (1980), Numerical Heat Transfer and Fluid Flow. McGraw-Hill USA.

Peterson P.F., Greenspan E., Zweibaum N., Scarlat R.O., Huddar L.R., Cisneros A.T., (2014), Technical Description of the Mark 1 Pebble-Bed Fluoride-Salt-Cooled HighTemperature Reactor (PB-FHR) Power Plant, Technical Description of the Mark 1 Pebble-Bed Fluoride-Salt-Cooled High-Temperature Reactor (PB-FHR) Power Plant,. University of California, Berkeley, USA. 
Pince B.E., Ball S.J., Engel J.R., Haubenreich P.N., Kerlin T.W., (1968), Zero-power physics experiment on the molten-salt reactor experiment, Technical Report,ORNL-4233.

Saad Y., Schultz M.H., (1986), GMRES: A generalized minimal residual algorithm for solving nonsymmetric linear systems. SIAM Journal on scientific and statistical computing 7 , 856-869.

Scarlat R.O., Laufer M.R., Blandford E.D., Zweibaum N., Krumwiede D.L., Cisneros A.T., Andreades C., Forsberg C.W., Greenspan E., Hu L.-W., (2014), Design and licensing strategies for the fluoride-salt-cooled, high-temperature reactor (FHR) technology. Progress in Nuclear Energy 77, 406-420.

Sellars J.R., Tribus M., Klein J., (1954), Heat transfer to laminar flow in a round tube or flat conduit: the Graetz probem extended, Technical report Wright air development center, USA.

Wang Y., Ge H.-W., Reitz R.D., (2010), Validation of mesh-and timestep-independent spray models for multi-dimensional engine CFD simulation. SAE Technical Paper, USA.

Zweibaum N., Guo Z., Huddar L., Peterson P., (2015), Validation of best estimate models for fluoride-salt cooled, high-temperature reactors using data from the compact integral effects test (CIET 1.0) facility, 16th International Topical Meeting on Nuclear Reactor Thermal Hydraulics (NURETH-16) Chicago,USA. 


\section{Figure list}

Fig. 1 Staggered mesh method schematic

Fig. 2 Angle interpolation for momentum CV in staggered mesh

Fig. 3 Simple hydrodynamic system (left) with corresponding incidence matrix (right)

Fig. 4 Mesh points for heat structure

Fig. 5 Inner heat source distribution and inner distance distribution

Fig. 6 Control logic tree for event sequences

Fig. 7 FANCY code architecture

Fig. 8 The Mk1 PB-FHR system (Krumwiede et al., 2014)

Fig. 9 Nodalization of the Mk1 PB-FHR in FANCY, based on equivalent model

Fig. 10 Loss of forced circulation (pump coastdown without scram)

Fig. 11 Coolant mass flow rate distribution during LOFC

Fig. 12 Loss of heat sink (failure of the power conversion system)

Fig. 13 Coolant mass flow rate distribution during LOHS 


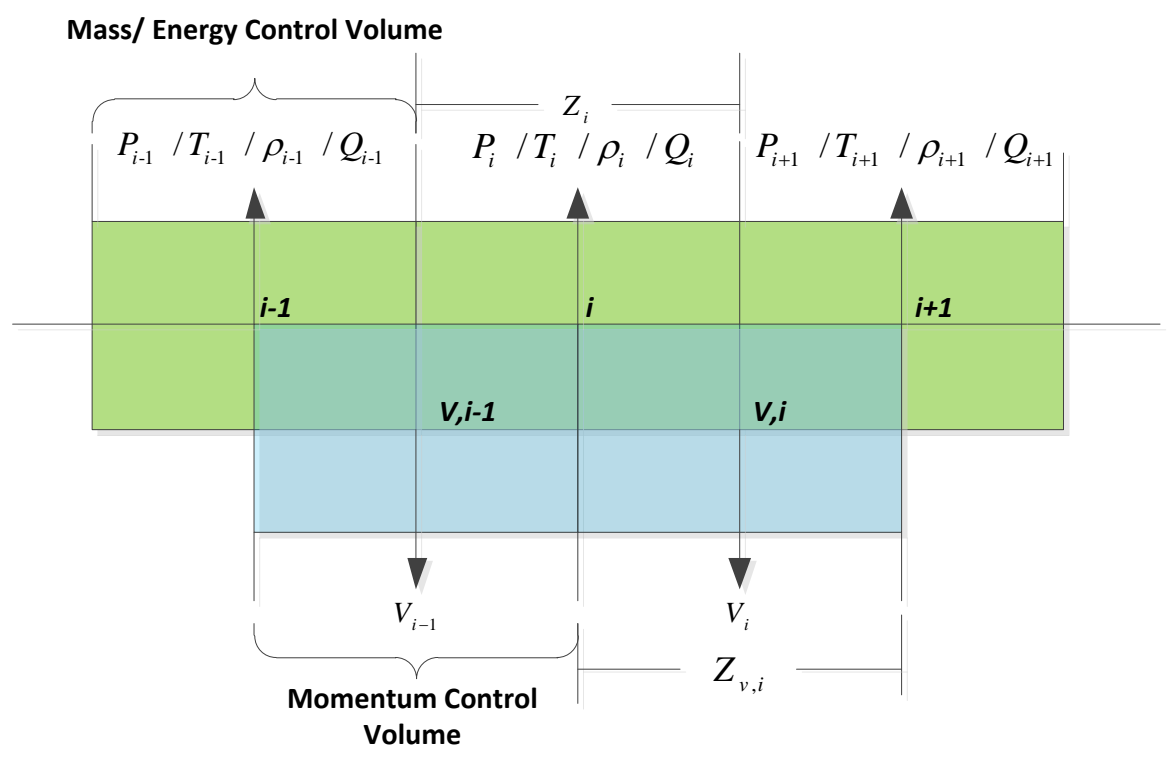

Fig. 1 Staggered mesh method schematic

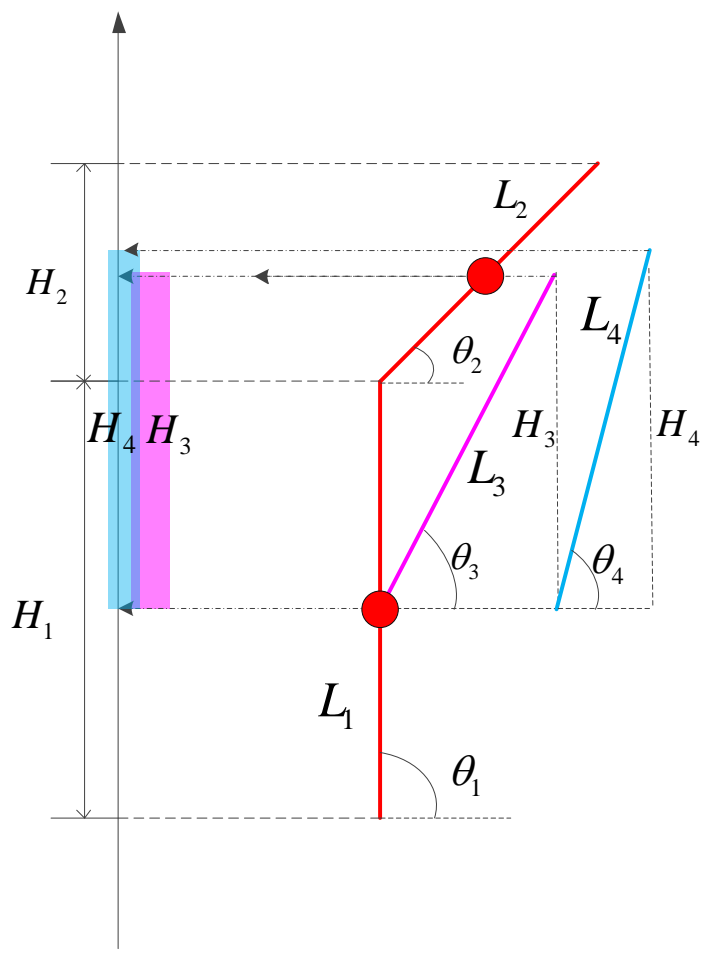

Fig. 2 Angle interpolation for momentum CV in staggered mesh 


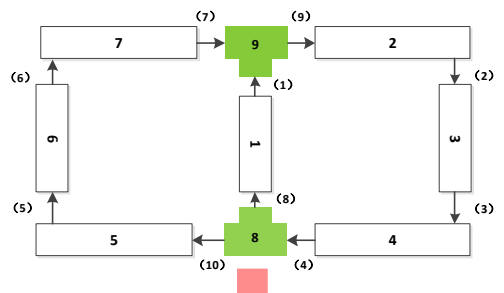

New Element-node (Branch-node) incidence matrix

Initial Element-node (Branch-node) incidence
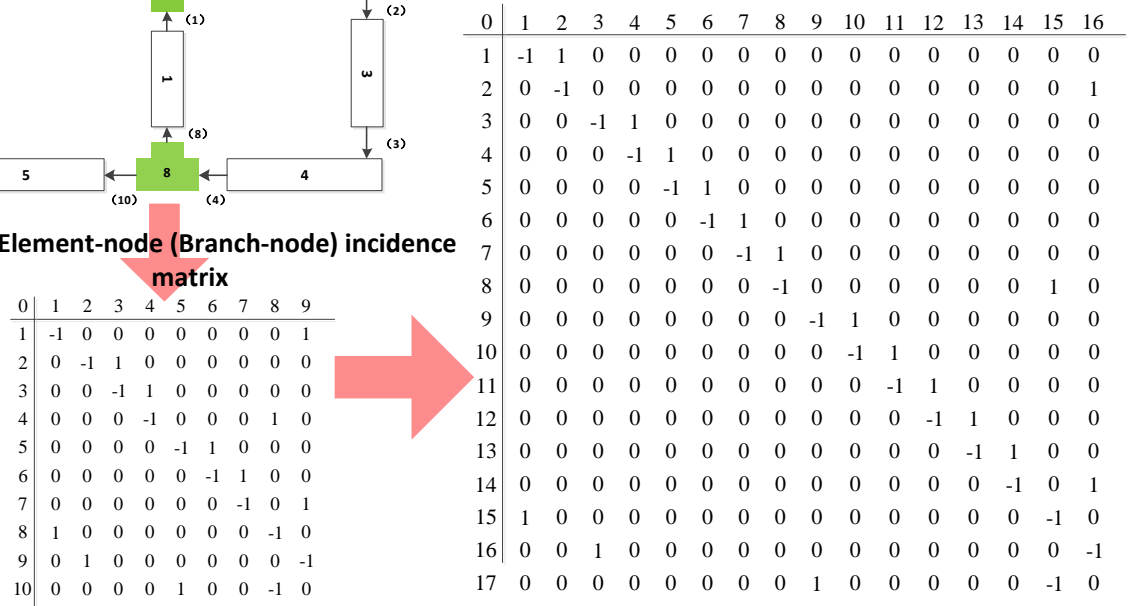

Fig. 3 Simple hydrodynamic system (left) with corresponding incidence matrix (right)

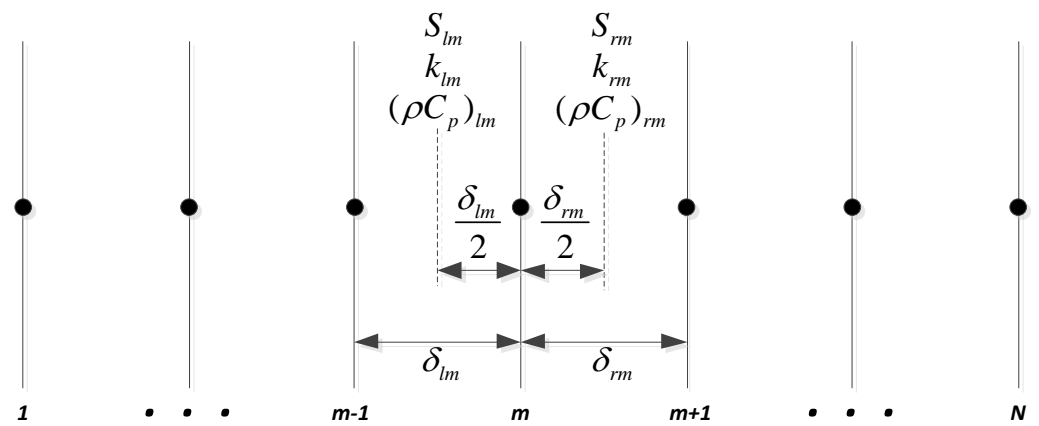

Fig. 4 Mesh points for heat structure

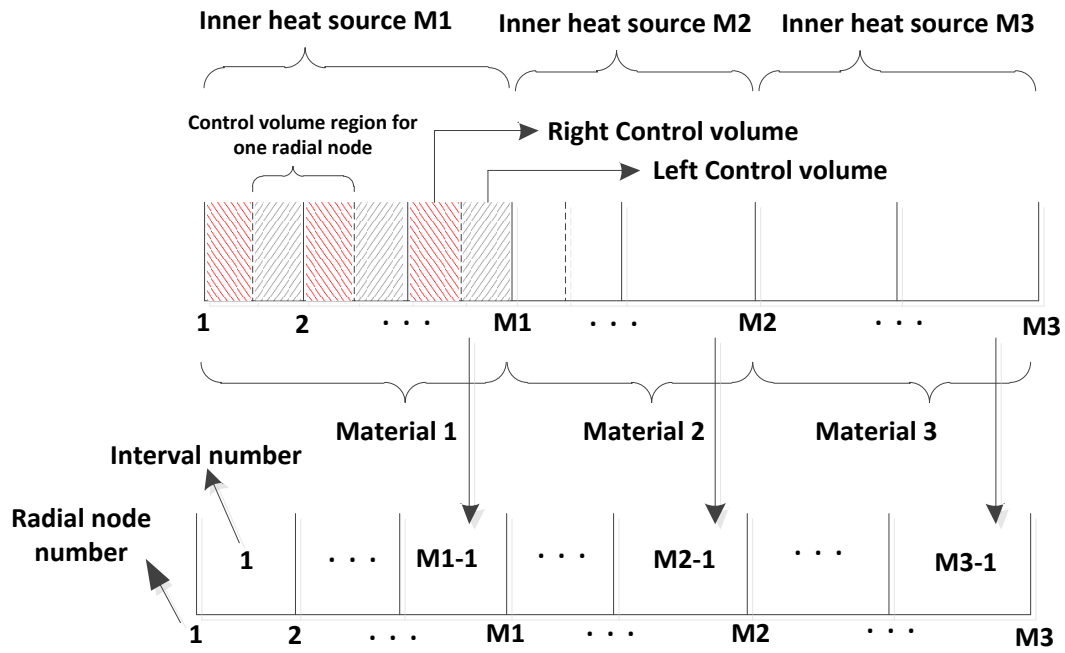

Fig. 5 Inner heat source distribution and inner distance distribution 


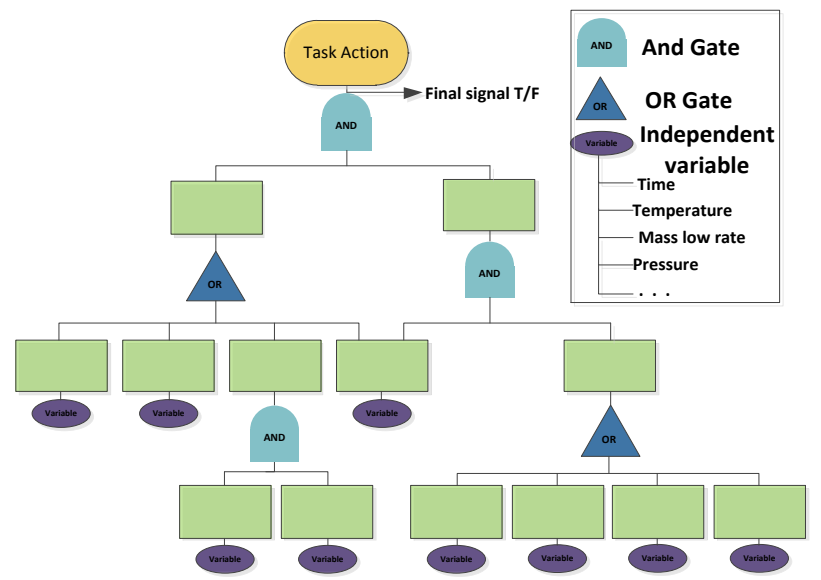

(a) Control logic tree (Boolean algebra)

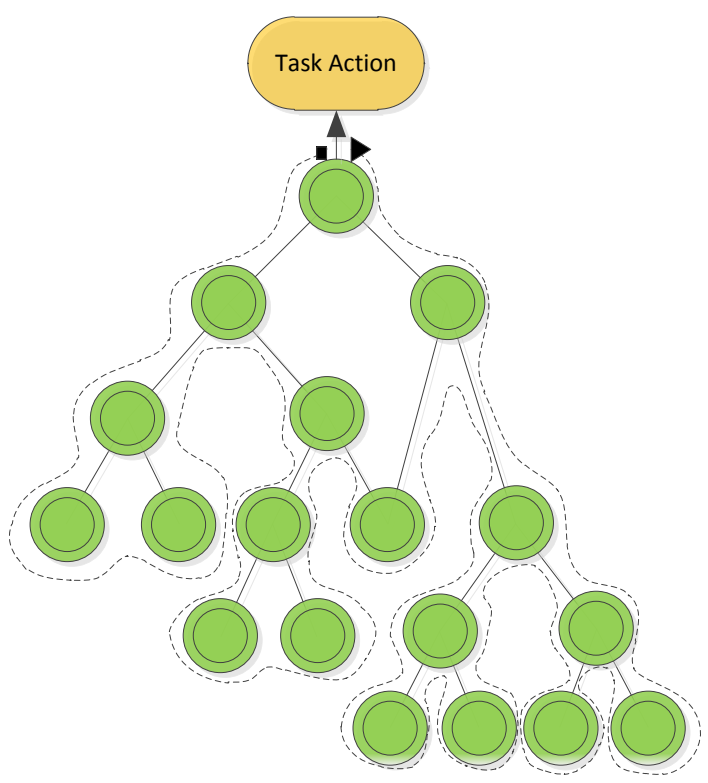

(b) Corresponding binary tree

Fig. 6 Control logic tree for event sequences 


\section{Code Architecture}

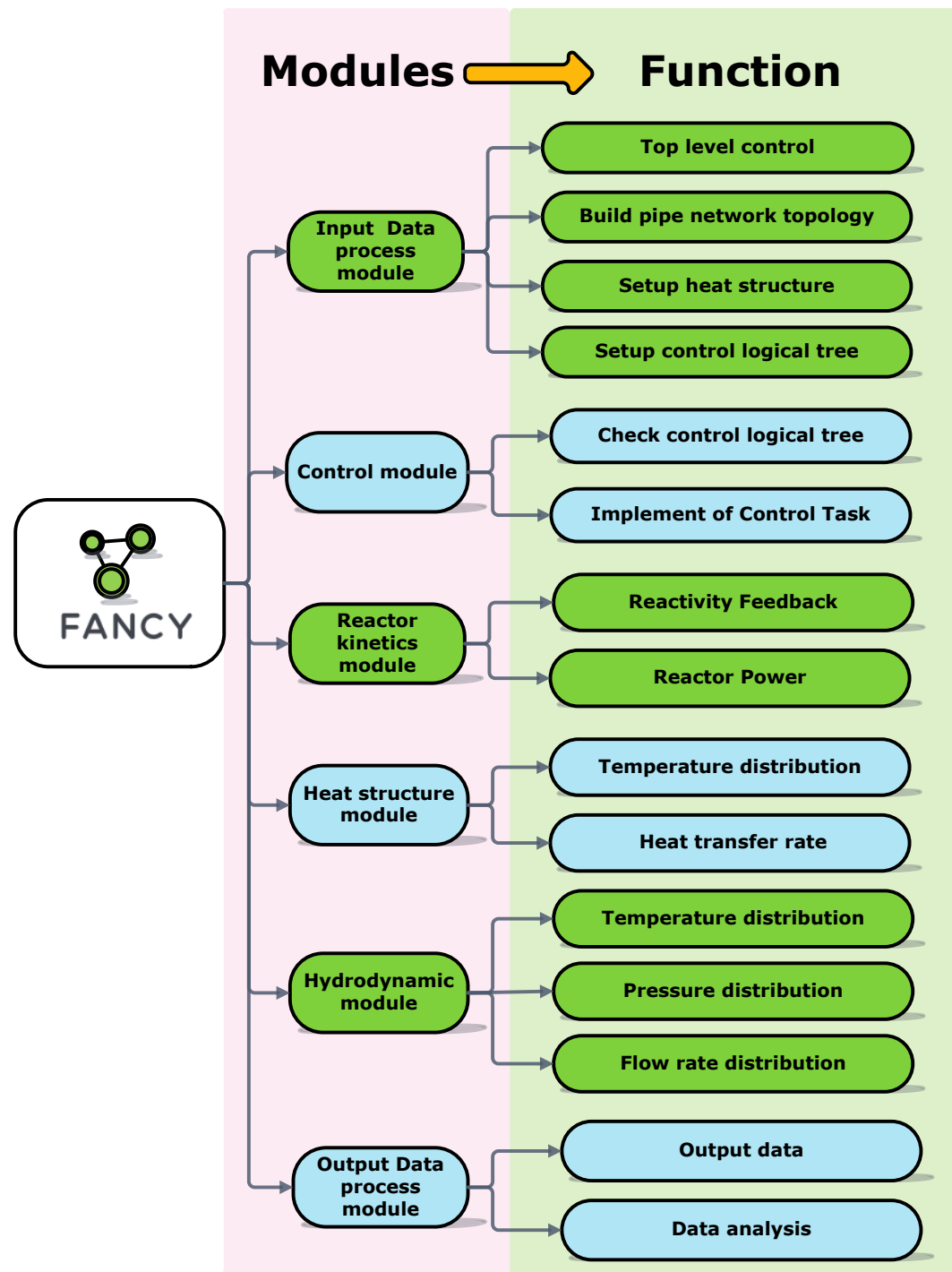

Fig. 7 FANCY code architecture 


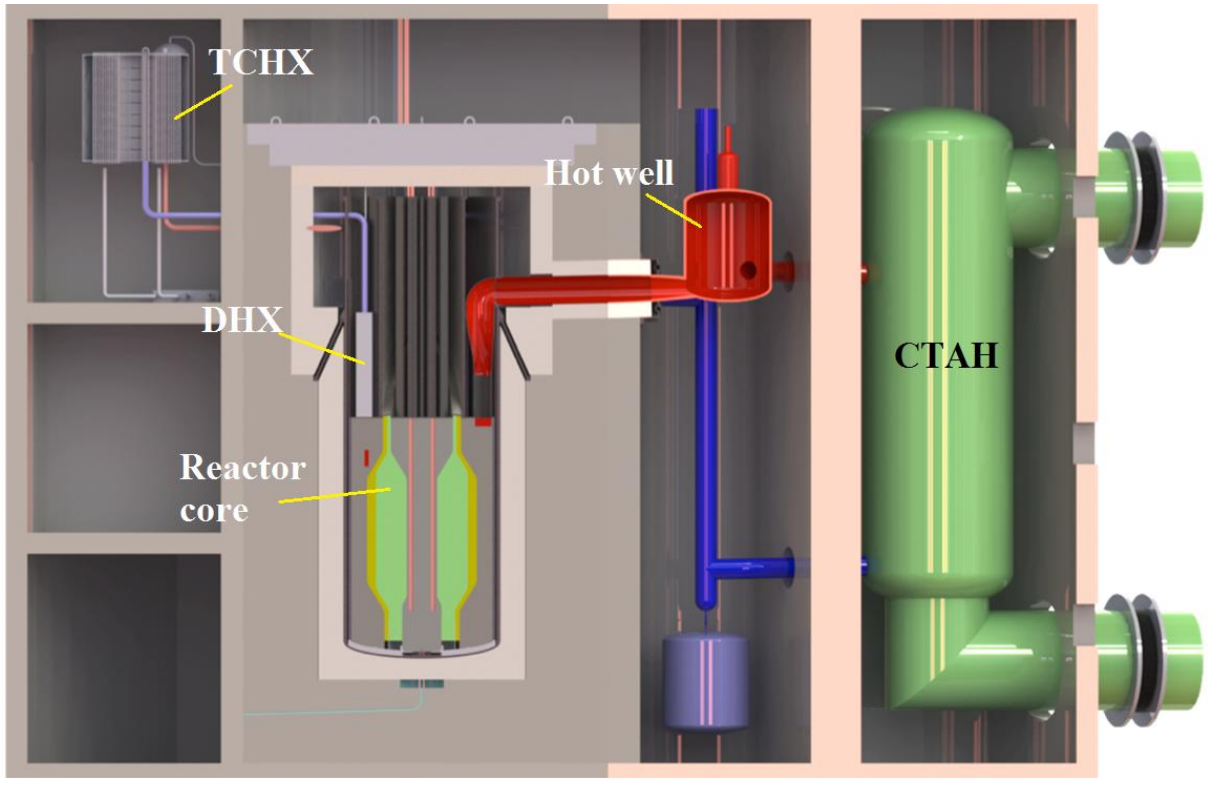

Fig. 8 The Mk1 PB-FHR system (Krumwiede et al., 2014) 


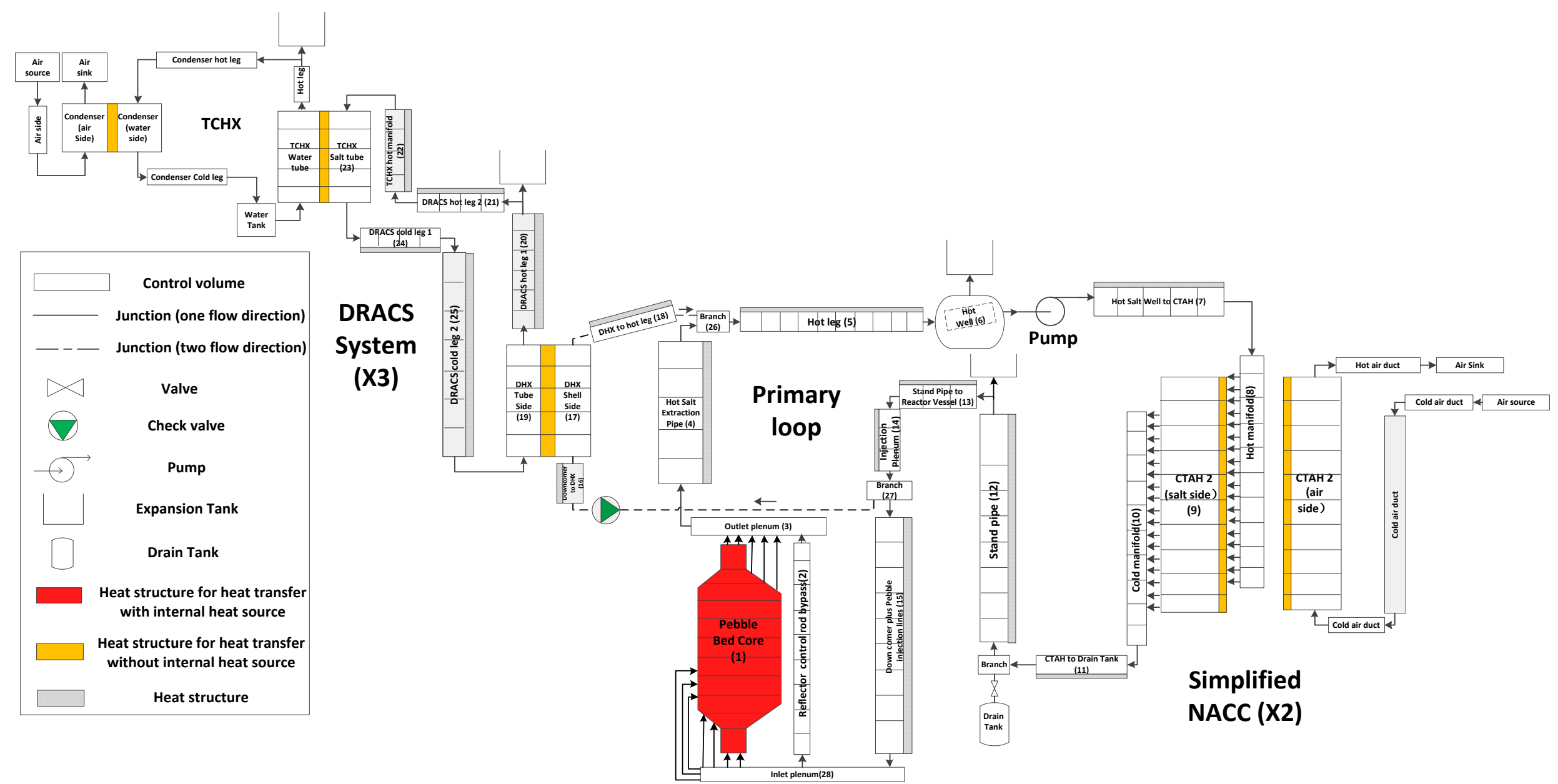

Fig. 9 Nodalization of the Mk1 PB-FHR in FANCY, based on equivalent model 


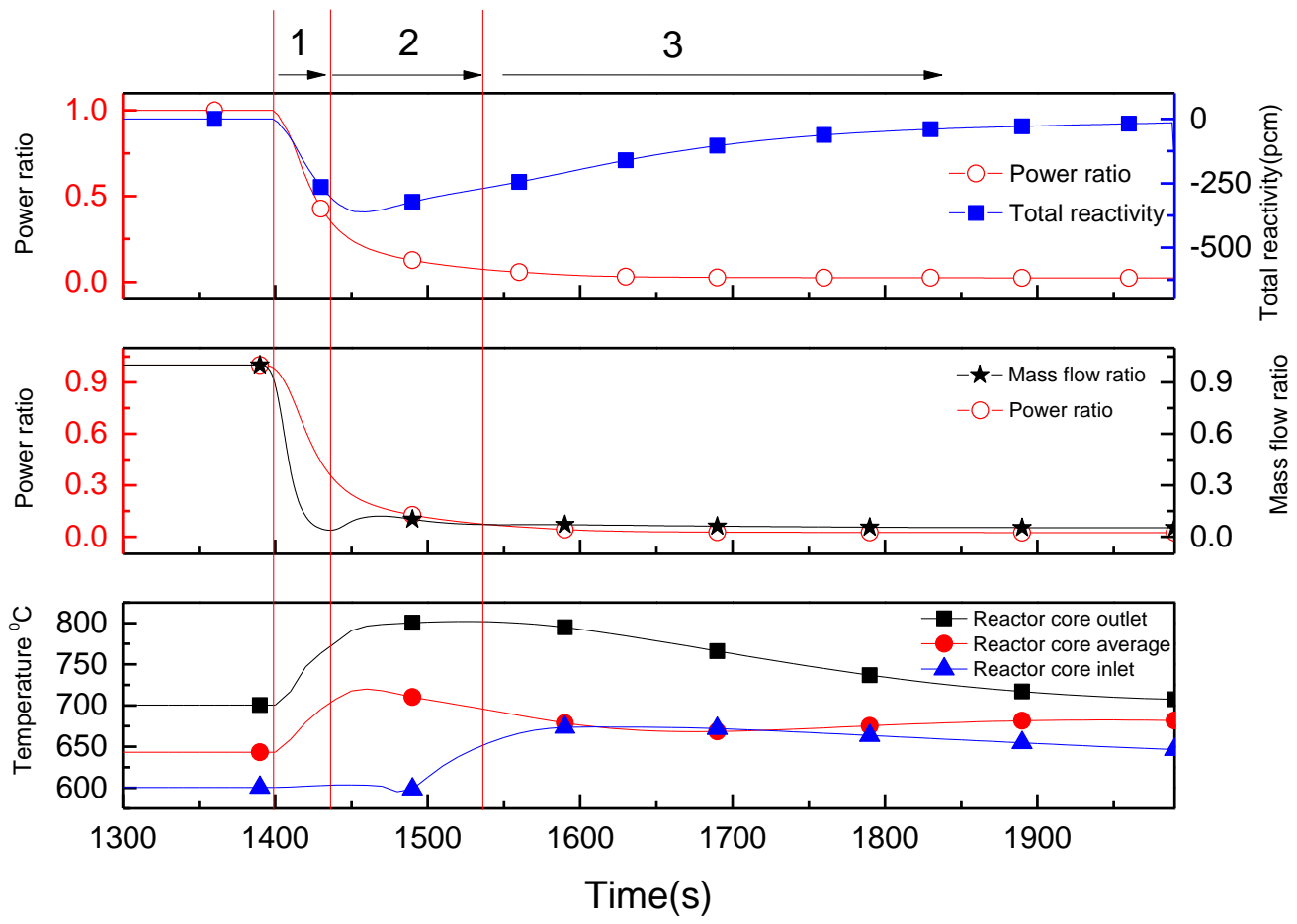

Fig. 10 Loss of forced circulation (pump coastdown without scram)

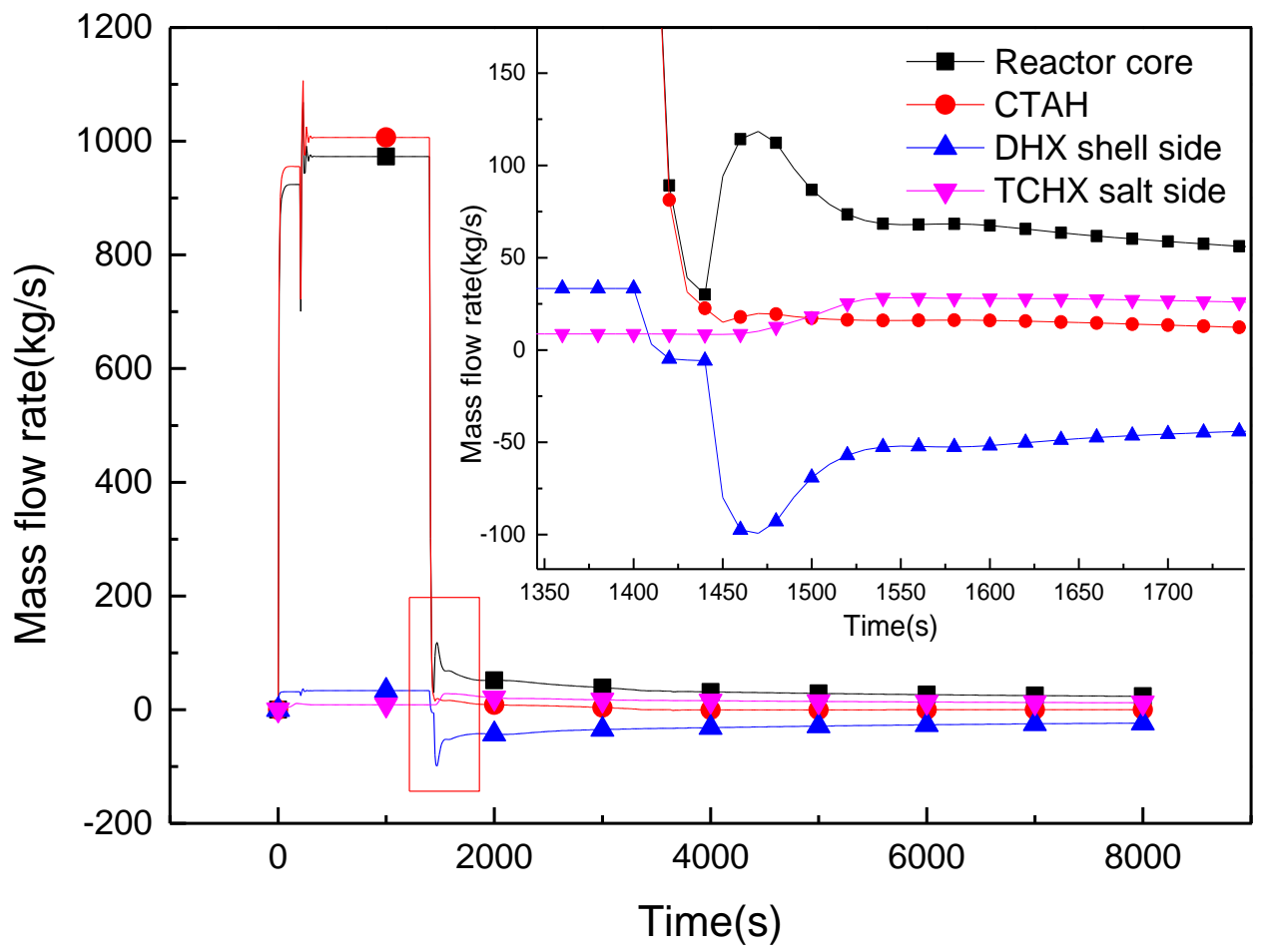

Fig. 11 Coolant mass flow rate distribution during LOFC 


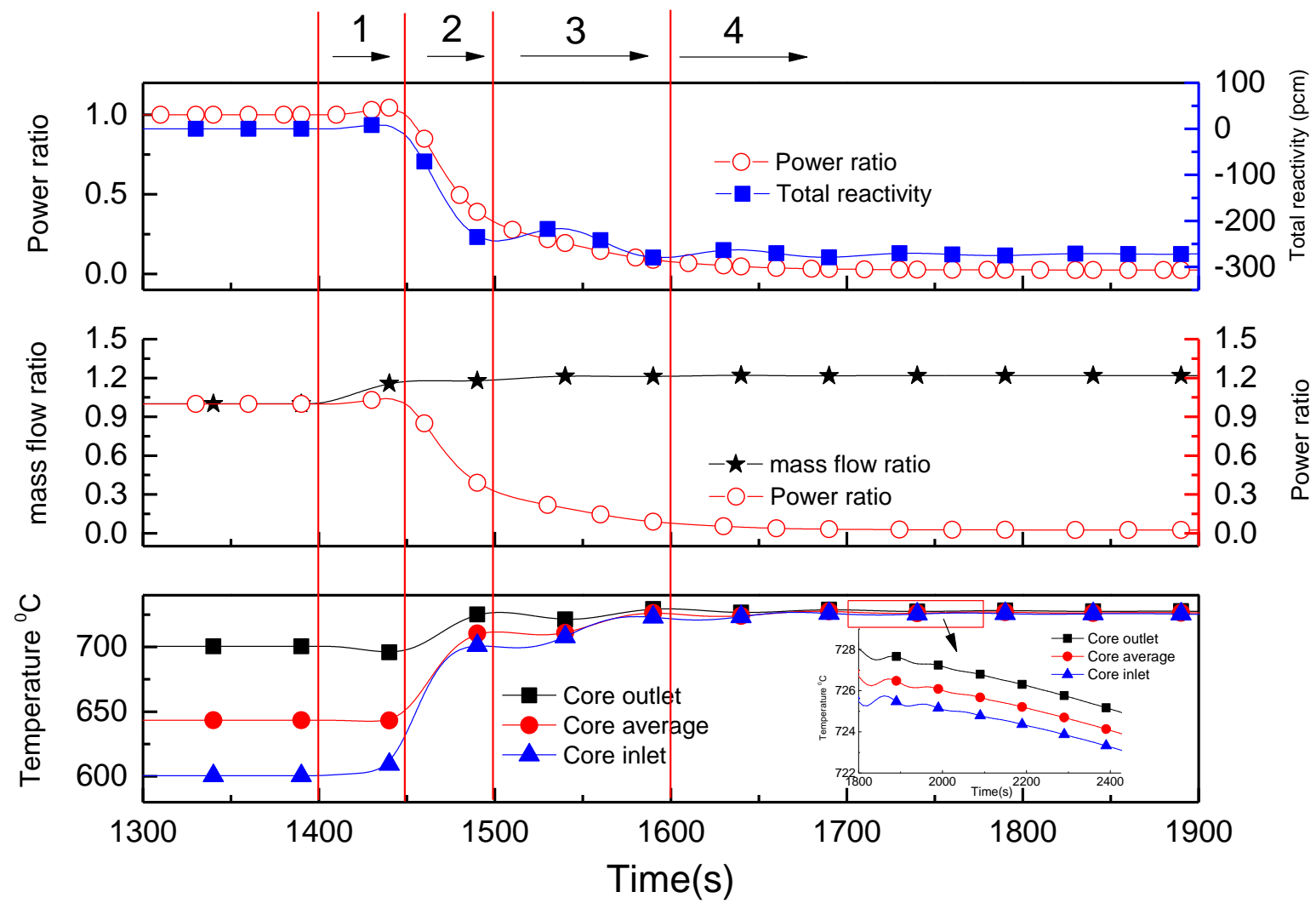

Fig. 12 Loss of heat sink (failure of the power conversion system) 


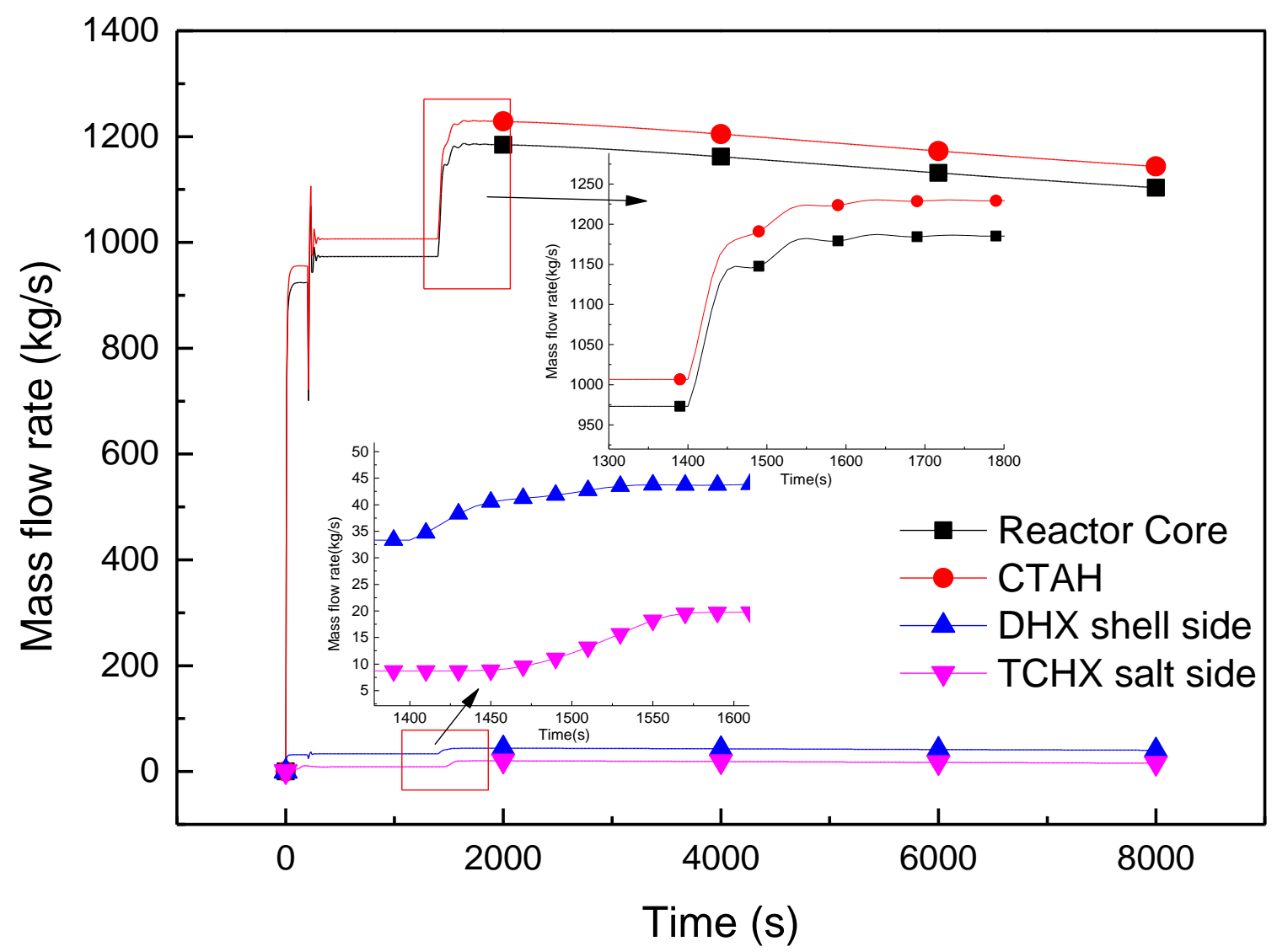

Fig. 13 Coolant mass flow rate distribution during LOHS 


\section{Table list}

Table 1 Friction factor and Nusselt number correlation models

Table 2 Temperature coefficients of reactivity for the Mk1 PB-FHR

Table 1 Friction factor and Nusselt number correlation models

\begin{tabular}{|c|c|}
\hline \multirow[b]{2}{*}{$\begin{array}{l}\text { Component } \\
\text { Pipe, branch, } \\
\text { heat transfer } \\
\text { channel }\end{array}$} & Friction factor \\
\hline & $\begin{array}{l}f_{L}=\frac{64}{\operatorname{Re} \phi_{s}}(0 \leq \operatorname{Re} \leq 2,200) \\
f_{L, T}=\left(3.75-\frac{8250}{\operatorname{Re}}\right)\left(f_{T, 3000}-f_{L, 2200}\right)+f_{L, 2200}(2,200 \leq \operatorname{Re} \leq 3,000)\end{array}$ \\
\hline Reactor core & $\begin{array}{l}\frac{1}{\sqrt{f_{T}}}=-2 \log _{10}\left(\frac{\varepsilon}{3.7 D}+\frac{2.51}{\operatorname{Re}}\left[1.114-2 \log _{10}\left(\frac{\varepsilon}{D}+\frac{21.25}{\operatorname{Re}^{0.9}}\right)\right]\right)(\operatorname{Re} \geq 3000) \\
f=\frac{(1-\varepsilon)}{\varepsilon^{3}}\left(\frac{150(1-\varepsilon)}{\operatorname{Re}}+1.75\right)(0.1<\operatorname{Re} /(1-\varepsilon)<500) \quad(\text { Ergun, } 1952)\end{array}$ \\
\hline Component & $\begin{array}{l}\text { Nusselt number } \\
\mathrm{Nu}=4.36 \text { (laminar forced convection) (Sellars et al., 1954) }\end{array}$ \\
\hline \multirow[t]{2}{*}{$\begin{array}{l}\text { Pipe, branch, } \\
\text { heat transfer } \\
\text { channel }\end{array}$} & 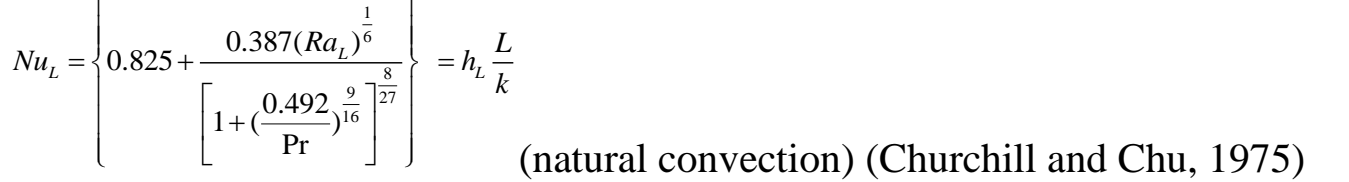 \\
\hline & $N u=0.023 \operatorname{Re}^{0.8} \operatorname{Pr}^{n}=h \frac{D}{K} \quad$ (turbulent forced convection) (Dittus and Boelter, 1985) \\
\hline Reactor core & $N u=2+1.1 \operatorname{Pr}^{1 / 3} \operatorname{Re}^{0.6}$ (porous media) (Nield and Bejan, 2006) \\
\hline
\end{tabular}

Table 2 Temperature coefficients of reactivity for the Mk1 PB-FHR

\begin{tabular}{cc}
\hline Component & Mk1 PB-FHR temperature reactivity coefficient $(\mathrm{pcm} / \mathrm{K})$ \\
\hline Fuel & -3.8 \\
Coolant & -1.8 \\
Inner graphite reflector & +0.9 \\
Graphite moderator & -0.7 \\
Outer graphite reflector & +0.9 \\
\hline
\end{tabular}

